\section{Michigan Technological

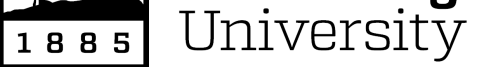

Michigan Technological University Digital Commons @ Michigan Tech

7-16-2015

\title{
In Situ Formation of Substrate Release Mechanisms for Gas Metal Arc Weld Metal 3-D Printing
}

Amberlee S. Haselhuhn

Michigan Technological University

Bas Wijnen

Michigan Technological University

Gerald C. Anzalone

Michigan Technological University

Paul G. Sanders

Michigan Technological University

Joshua M. Pearce

Michigan Technological University

Follow this and additional works at: https://digitalcommons.mtu.edu/materials_fp

\section{Recommended Citation}

A.S. Haselhuhn, B. Wijnen, G. C. Anzalone, P. G. Sanders, J. M. Pearce, In Situ Formation of Substrate Release Mechanisms for Gas Metal Arc Weld Metal 3-D Printing. Journal of Materials Processing Technology. 226, pp. 50-59 (2015). http://digitalcommons.mtu.edu/materials_fp/57 
Preprint: A.S. Haselhuhn, B. Wijnen, G. C. Anzalone, P. G. Sanders, J. M. Pearce, In Situ Formation of Substrate Release Mechanisms for Gas Metal Arc Weld Metal 3-D Printing. Journal of Materials Processing Technology. 226, pp. 50-59 (2015) DOI: 10.1016/j.jmatprotec.2015.06.038

\title{
In Situ Formation of Substrate Release Mechanisms for Gas Metal Arc Weld Metal 3-D Printing
}

\author{
Amberlee S. Haselhuhn ${ }^{1}$, Bas Wijnen ${ }^{1}$, Gerald C. Anzalone ${ }^{1}$, Paul G. Sanders ${ }^{1}$, Joshua M. Pearce ${ }^{1,2}$ \\ ${ }^{1}$ Department of Materials Science \& Engineering, Michigan Technological University, Houghton, MI 49931, USA \\ ${ }^{2}$ Department of Electrical \& Computer Engineering, Michigan Technological University, Houghton, MI 49931, USA
}

The corresponding author’s contact information: pearce@mtu.edu

Keywords: 3-D printing, additive manufacturing, aluminum, steel, in situ formation, distributed manufacturing, gas metal arc weld, GMAW, metal processing, metal inert gas welding, MIG welding, open-source, open-source electronics, open-source hardware, personal fabrication, rapid prototyping

\begin{abstract}
This study provides an in-depth investigation into low-cost and no-cost substrate release mechanisms that allow gas metal arc weld 3-D printed ER4043 aluminum and ER70S-6 steel parts to be removed from a reusable print substrate with minimal energy. Aluminum oxide, boron nitride, and titanium nitride coatings were evaluated as possible substrate release agents for aluminum printing. Additionally, the in situ formation of substrate release agents such as intermetallics and oxides were tested for both aluminum and steel printing. Testing was performed with a modified Charpy impact tester to remove 3-D printed metal parts from an 1100 aluminum or A36 low carbon steel print substrate to assess the impact energy required for removal. Specimen porosity was measured prior to sectioning and microstructural analysis, hardness traverses were measured across the specimens, and the elastic and shear moduli of the parts were analyzed via ultrasonic methods. All of the employed substrate release mechanisms minimized weld penetration and, in some instances, formed a brittle phase with the print substrate that allowed the specimens to be removed with minimal impact energy. These results thus provide methods with the removal of metal 3-D printed parts from print substrates with no specialized tooling or equipment conducive to distributed manufacturing.
\end{abstract}

\section{Introduction}

Additive manufacturing, commonly known as 3-D printing, has progressed beyond prototyping and tooling (Sachs et al. 1992) and is now changing the state of manufacturing across the globe (Campbell et al., 2011). This type of manufacturing is already being used to produce functional components for custom biomedical implants, dental prostheses, non-structural aircraft components, custom tooling, and thousands of customized consumer parts such as jewelry, sculptures, phone cases, and more (Wohlers \& Caffrey, 2014). The ability to quickly model, change, and print designs makes manufacturing possible in small or large quantities, including end-user manufacturing on a micro-scale (Wittbrodt et al., 2013) and the concomitant social change (Ratto and Ree, 2012).

Traditional metal printing methods utilizing sintering, typically with laser or electron beam sources, are expensive due to the high capital and operating cost of the 3-D printing equipment employed. For instance, Berman (2012) stated that industrial-grade printers capable of rapid prototyping can cost on the order of hundreds of thousands of dollars; Peels (2014) reported that some direct metal laser sintering machines cost as much as \$1.5 million. Often specialized and expensive facilities are needed to house the equipment (e.g. blast-protected rooms for metal powder printing). Expensive, energy intensive, and time-consuming methods are then needed to remove metal 3-D printed parts from the substrates such as wire electrical discharge machining (EDM). As a result, additive manufacturing with metal is largely isolated to large corporations possessing the means to equip and maintain these expensive facilities.

Gas metal arc welding (GMAW) may be one low-cost solution to three dimensionally print metals (Anzalone et al., 2013). The GMAW process is described by O’Brien (1991) and Holliday (1993). GMAW utilizes a gas-shielded metal wire fed through a nozzle that is a consumable electrode heated by an electrical arc established between the wire and a metallic substrate. This arc melts the electrode and a portion of the weld substrate, depositing metal into the substrate's weld pool. The gas shield protects the hot metal from atmospheric gases and humidity that can cause 
Preprint: A.S. Haselhuhn, B. Wijnen, G. C. Anzalone, P. G. Sanders, J. M. Pearce, In Situ Formation of Substrate Release Mechanisms for Gas Metal Arc Weld Metal 3-D Printing. Journal of Materials Processing Technology. 226, pp. 50-59 (2015) DOI: 10.1016/j.jmatprotec.2015.06.038

porosity or oxidation. The composition of the gas shield mixtures can be tuned to modify weld pool geometry, penetration, and porosity while also stabilizing the arc and minimizing weld spatter (Holliday, 1993). For instance, helium additions to the argon gas in aluminum welding yields a more uniform weld pool geometry with less porosity at the expense of lower arc stability and more weld spatter (O’Brien, 1991).

The GMAW-based open-source design for a 3-D printer by Anzalone et al. (2013) was inspired by a Rostock RepRap printer, (a self-replicating rapid prototyper (Jones et al., 2011)); the printer features a 3-axis stage upon which the print substrate is clamped (Reprap Org, 2014). A stationary weld gun is the print head which delivers material to the substrate, with a common GMAW welder is used to print layers in a single-pass, multi-layer regime. This printer is capable of printing both aluminum and steel alloys to produce near net-shape parts.

As O’Brien (1991) and Holliday (1993) describe, welding shield gases are essential to forming a strong weld joint in GMAW. However, the formation of a strong, weld-like joint between a 3-D printed metal part and a metallic substrate is undesirable. Strong adhesion between the part and the substrate makes separation of the part from the substrate more difficult and the substrate must be sacrificed so it can only be used once. It is desirable to 3D print a metal part onto a metal substrate, remove the part with little force, and have the ability to re-use the substrate with minimal post-print processing.

A previous study explored the use of coatings, such as oxides and nitrides, and welding of dissimilar metals to prevent adhesion between the 3-D printed metal part and the substrate (Haselhuhn et al., 2014). Nitride coatings and printing aluminum on steel substrates were shown to be effective at minimizing part-substrate adhesion with aluminum parts. In this paper, this preliminary work has been further analyzed, extended to steel printing, and new substrate release mechanisms such as omission of shield gas and application of alternate coatings are explored (Table 1).

Table 1. Substrate Release Mechanisms Analyzed by this Study

\begin{tabular}{|c|c|c|c|c|c|}
\hline Mechanism & $\begin{array}{c}\text { Print } \\
\text { Material }\end{array}$ & Substrate Type & Coating Type & $\begin{array}{c}\text { Coating } \\
\text { Thickness }(\mu \mathrm{m})\end{array}$ & $\begin{array}{c}\text { Shield Gas Use } \\
1^{\text {st }} \text { Layer }\end{array}$ \\
\hline \multirow[t]{2}{*}{ Control } & ER70S-6 & $\begin{array}{c}\text { A36 Low Carbon } \\
\text { Steel }\end{array}$ & None & 0 & $\begin{array}{l}25 \% \text { CO2 in } \\
\text { Argon }\end{array}$ \\
\hline & ER4043 & 1100 Aluminum & None & 0 & Argon \\
\hline \multirow{2}{*}{$\begin{array}{l}\text { Alternate } \\
\text { Settings }\end{array}$} & ER70S-6 & $\begin{array}{c}\text { A36 Low Carbon } \\
\text { Steel }\end{array}$ & None & 0 & None \\
\hline & ER4043 & 1100 Aluminum & None & 0 & None \\
\hline \multirow[t]{2}{*}{ Intermetallics } & ER4043 & $\begin{array}{c}\text { A36 Low Carbon } \\
\text { Steel }\end{array}$ & None & 0 & Argon \\
\hline & ER4043 & 1100 Aluminum & $\begin{array}{l}\text { Aluminum } \\
\text { Oxide }\end{array}$ & 18.50 & Argon \\
\hline \multirow[t]{2}{*}{ Coatings } & ER4043 & 1100 Aluminum & Boron Nitride & 5.95 & Argon \\
\hline & ER4043 & 1100 Aluminum & $\begin{array}{l}\text { Titanium } \\
\text { Nitride }\end{array}$ & 6.25 & Argon \\
\hline
\end{tabular}

Manipulation of shielding gas was found to obviate the need for additional coatings to minimize adhesion between the sample and the substrate. In this case, adhesion modifiers were formed in situ and weld penetration was limited, allowing the sample to be removed from the substrate with minimal energy. The development of these substrate release mechanisms (Table 1) is described in depth and evaluated in terms of their efficacy and practicality with both aluminum and steel parts. The strength of adhesion was evaluated using modified Charpy impact testing. The sample porosity, microstructures, hardness, and ultrasonic modulus were analyzed to evaluate 3-D printed part quality. 
Preprint: A.S. Haselhuhn, B. Wijnen, G. C. Anzalone, P. G. Sanders, J. M. Pearce, In Situ Formation of Substrate Release Mechanisms for Gas Metal Arc Weld Metal 3-D Printing. Journal of Materials Processing Technology. 226, pp. 50-59 (2015) DOI: 10.1016/j.jmatprotec.2015.06.038

\section{Materials and Methods \\ Description of the 3-D Metal Printer}

The 3-D metal printer and open-source software tool chain used in this study has been previously described by Haselhuhn et al. (2014) (Figure 1). A Millermatic 140 with an M-100 weld gun was used to print steel parts whereas aluminum parts were printed with a Miller Spoolmate 100 weld gun. The weld gun remained stationary while a computer numeric controlled 3-axis stage provided the necessary motion to 3-D print a metal part. Welder and printer settings were manually adjusted to achieve high-quality prints with a maximum print diameter approximately $80 \mathrm{~mm}$. Weld-grade argon shield gas was used during aluminum printing and RC25, a gas mixture of $25 \% \mathrm{CO}_{2}$ in argon, was used as a cover gas for steel printing.

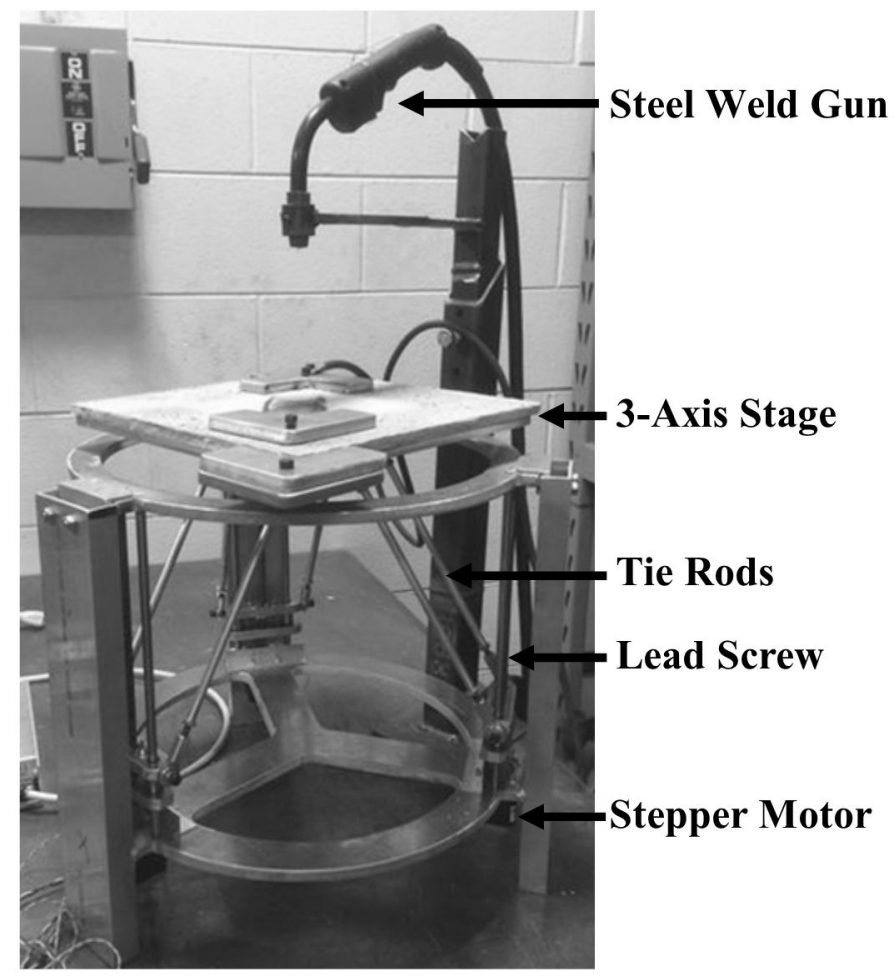

Figure 1. Labeled photograph of the GMAW-based metal 3-D printer shown with the M-100 weld gun for printing steel

\section{Preparation of Print Substrates}

Degreased 1100 aluminum and ASTM A36 low carbon steel sheets, $152.4 \times 152.4 \times 6.35 \mathrm{~mm}$ in size, were used as print substrates. Aerosol-based aluminum oxide, boron nitride, and titanium nitride coatings (ZYP Coatings, Inc.) were evenly sprayed onto separate 1100 aluminum substrates prior to printing (Table 1: Coating Mechanism). The coatings were smooth and geometrically uniform to prevent dimensional variation that could distort layer and part geometries. The thickest possible coating was applied that would still allow a weld arc to form between the weld gun and the print substrate. At coating thicknesses in excess of those reported, the welder could not produce a stable arc and welding did not occur. The coatings were allowed to dry completely in ambient air prior to printing. Samples were weighed before $\left(\mathrm{W}_{\text {initial }}\right)$ and after $\left(\mathrm{W}_{\text {final }}\right)$ application of the coating and coating thickness was calculated based upon the average coating weight across the surface area (SA) of the substrate given a known coating density ( $\left.\rho_{\text {coating }}\right)$ (Equation 1$)$. 
Preprint: A.S. Haselhuhn, B. Wijnen, G. C. Anzalone, P. G. Sanders, J. M. Pearce, In Situ Formation of Substrate Release Mechanisms for Gas Metal Arc Weld Metal 3-D Printing. Journal of Materials Processing Technology. 226, pp. 50-59 (2015) DOI: 10.1016/j.jmatprotec.2015.06.038

$$
\text { Thickness }=\frac{W_{\text {final }}-W_{\text {initial }}}{\rho_{\text {coating }} * S A}
$$

A subset of aluminum substrates was left in the uncoated state to serve as controls. Coatings were not applied to steel substrates as preliminary work indicated that they did not survive the steel welding environment. Five samples per treatment condition were prepared.

\section{Printing of Samples}

Standard ER4043 aluminum GMAW wire (Blue Demon Welding Products), 0.030 inches $(0.762 \mathrm{~mm})$ in diameter, and standard ER70S-6 low carbon steel GMAW wire (Hobart), 0.023 inches $(0.584 \mathrm{~mm})$ in diameter were used as the print material. One inch $(25.4 \mathrm{~mm})$ cube samples were printed directly onto the center of the prepared substrates (Table 2; Figure 2).

Table 2. 3-D metal print parameters used to produce 1” cubes

\begin{tabular}{|c|c|c|c|c|c|c|c|c|}
\hline $\begin{array}{c}\text { Print } \\
\text { Material }\end{array}$ & Mechanism(s) & $\begin{array}{l}\text { Weld } \\
\text { Voltage } \\
\text { (V) }\end{array}$ & $\begin{array}{l}\text { Weld } \\
\text { Current } \\
\text { (A) }\end{array}$ & $\begin{array}{c}\text { Wire } \\
\text { Feed Rate } \\
\text { (mm/sec) }\end{array}$ & $\begin{array}{c}\text { Print } \\
\text { Velocity } \\
\text { (mm/sec) }\end{array}$ & $\begin{array}{l}\text { Wire } \\
\text { Stick- } \\
\text { Out } \\
\text { (mm) }\end{array}$ & $\begin{array}{l}\text { Cover } \\
\text { Gas }\end{array}$ & $\begin{array}{c}\text { Gas } \\
\text { Flow } \\
\text { Rate } \\
\text { (L/sec) }\end{array}$ \\
\hline \multirow[t]{2}{*}{ ER70S-6 } & $\begin{array}{l}\text { Control } \\
\text { Alternate } \\
\text { Settings: } 2^{\text {nd }}-15^{\text {th }} \\
\text { Layers }\end{array}$ & 16 & 76 & 102 & 5.23 & 8 & RC25 & 0.13 \\
\hline & $\begin{array}{c}\text { Alternate } \\
\text { Settings: } 1^{\text {st }} \text { Layer } \\
\text { Only }\end{array}$ & 14 & 65 & 133 & 5.23 & 11 & None & 0.00 \\
\hline ER4043 & All Mechanisms ${ }^{\mathrm{a}}$ & 15 & 72 & 149 & 15.00 & 14 & Argon & 0.22 \\
\hline
\end{tabular}

a Shield gas was not used to print the $1^{\text {st }}$ layer of some samples, as described in Table 1.
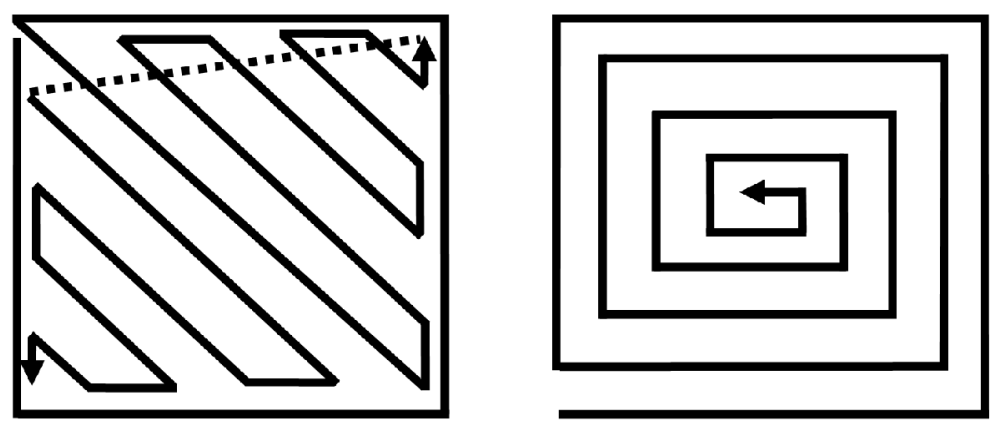

Figure 2. Alternating print paths for the 3-D metal printer as viewed in the direction of the z-axis. The lines in this schematic only represent the print paths taken by the printer and the print was a solid part. The starting point for each layer alternated between the cube's four corners.

Alternating the print path between layers improved the in-fill between weld beads improving overall print quality. A 60 second pause was applied between each layer when printing with aluminum. A similar approach was applied when printing steel cubes with a 10 minute pause after the first layer, 60 second pauses after the $3^{\text {rd }}$ and $5^{\text {th }}$ layers, followed by 2 minute pauses after every other subsequent layer. These pauses were performed to allow the sample to cool sufficiently to maintain dimensional tolerance and also to prevent the welder from overheating. Allowing the first steel layer to cool completely before printing additional layers was found in preliminary experiments to reduce 
Preprint: A.S. Haselhuhn, B. Wijnen, G. C. Anzalone, P. G. Sanders, J. M. Pearce, In Situ Formation of Substrate Release Mechanisms for Gas Metal Arc Weld Metal 3-D Printing. Journal of Materials Processing Technology. 226, pp. 50-59 (2015) DOI: 10.1016/j.jmatprotec.2015.06.038

the energy required to remove the part from the substrate. Each specimen was water quenched immediately following print completion. Five samples were printed per group and their final dimensions were measured with digital calipers $( \pm 0.01 \mathrm{~mm})$.

\section{Sample Testing and Analysis}

The impact strength of each sample-substrate interface was tested using a modified Charpy impact tester (Tinius Olsen) (Figure 3). This modified test apparatus removed the entire 3-D printed specimen from the print substrate and did not shear off any of the printed layers. A standard $1 \mathrm{lb}(0.45 \mathrm{~kg})$ claw hammer head was used as the striker rather than the traditional wedge striker to simulate the effects of removing the sample from the substrate using a standard hammer by hand. However, as the weight of the hammer head was much smaller than a typical striker arm used with Charpy impact testing, the weight of the pivot arm was not negligible and was included in the calculation as a friction term (Equation 2).

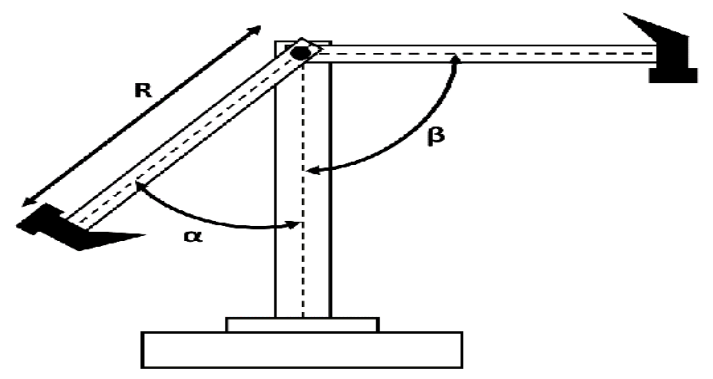

Figure 3. Schematic diagram of the modified Charpy impact tester.

Samples were securely wedged into place to avoid displacement during testing. The pivot arm was initially set to an angle of 90 degrees from vertical and released in a consistent manner using a lever mechanism. The pivot arm rotated about a fixed axis that only allowed in-line swing. The striking face of the hammer head was approximately the same size as the 3-D printed specimens and the specimens were situated vertically in the test apparatus such that the hammer squarely struck the specimens at or near the specimen centerpoint. The clearance between the hammer and the substrate was less than 3 millimeters. A high speed camera was used to capture images of the pendulum during and after striking the sample. Using NIH ImageJ software (Rasband, 2014), the maximum angle of the pivot arm after hitting the sample was measured. Knowing the mass of the pendulum (m), acceleration due to gravity (g), length of pivot arm to the center of hammer mass (R), the initial, stationary angle of the pendulum $(\beta)$, the final angle of the pendulum $(\alpha)$ following impact, and the energy loss associated with friction $\left(E_{f}\right)$, the impact energy $\left(\mathrm{E}_{\mathrm{i}}\right)$ was calculated (Equation 2). In a frictionless system, the initial and final angles would be equivalent. However, when the mass of the pendulum is low, friction can play a significant role in the final results. The frictional energy loss was determined by releasing the pendulum from a known initial angle without a specimen in the sample holder, measuring the final angle of the pendulum, and calculating an associated energy using the first half of Equation 2 in square brackets. Any specimens not removed by the Charpy impact were physically removed with a water cooled horizontal band saw for additional analysis.

$$
E_{i}=[m g R(\cos \alpha-\cos \beta)]-E_{f}
$$

Following Charpy impact testing, the porosity in the cube specimens was measured using the Archimedes Principle, following ASTM B962, "Standard Test Methods for Density of Compacted or Sintered Powder Metallurgy (PM) Products Using Archimedes' Principle” (2013). This measurement compares the weight of the 
Preprint: A.S. Haselhuhn, B. Wijnen, G. C. Anzalone, P. G. Sanders, J. M. Pearce, In Situ Formation of Substrate Release Mechanisms for Gas Metal Arc Weld Metal 3-D Printing. Journal of Materials Processing Technology. 226, pp. 50-59 (2015) DOI: 10.1016/j.jmatprotec.2015.06.038

specimen dry $\left(\mathrm{W}_{\text {dry }}\right)$ and when submerged in water $\left(\mathrm{W}_{\text {submerged }}\right)$ using a temperature corrected density $\left(\rho_{\text {water(T) }}\right)$ to determine density $\left(\rho_{\text {sample }}\right)$ (Equation 3$)$.

$$
\rho_{\text {sample }}=\frac{W_{d r y}}{W_{d r y}-W_{\text {submerged }}} * \rho_{\text {water }(T)}
$$

To measure the submerged weight of the sample, each sample was placed in distilled water and ultrasonically agitated prior to measurement. This agitation was performed to fill any open porosity, ensuring that only closed porosity influenced the final porosity measurement. By comparing the density of the specimen to a known standard density for the weld alloy ( $\left.\rho_{\text {standard}}\right)$, the specimen porosity (\% Porosity) was calculated (Equation 4$)$.

$$
\text { Porosity }=\frac{\rho_{\text {standard }}-\rho_{\text {sample }}}{\rho_{\text {standard }}} * 100
$$

A representative specimen from each group was sectioned twice using a slow speed diamond saw: once along the $\mathrm{x}$-axis and once along the $\mathrm{y}$-axis to produce 4 rectangular specimens each approximately $12.7 \times 12.7 \times 25.4$ $\mathrm{mm}$ in size. The specimens were vacuum impregnated with fluorescent epoxy to fill micro-cracks, porosity, or regions with poor infill between the weld beads. This fluorescent epoxy improved detection of smaller features in the microscope and also facilitated later polishing processes as it minimized the risk of collecting grinding media in the voids which would later scratch the polished surface. Aluminum samples were polished to $0.05 \mu \mathrm{m}$ with silica whereas the steel specimens were polished to $0.05 \mu \mathrm{m}$ with alumina. To enhance the microstructural features for microscopy work, the aluminum specimens were etched for 30 seconds in Keller's etchant whereas the steel specimens were etched with $2 \%$ nital solution for approximately 10 seconds.

The specimens were examined in a standard optical microscope and also in a Philips XL40 environmental scanning electron microscope in order to observe the microstructural features. Energy dispersive spectroscopy (EDS) was performed with particular emphasis near the interface between the print substrate and the first layer of the specimen to determine if any inclusions (oxides, nitrides, or aluminum-iron intermetallics) formed or if segregation of these compounds occurred within the specimen. EDS analyses were performed at $25 \mathrm{keV}$ accelerating voltage with a spot size of 6 and a collection time of 100 live time seconds. The goal was to determine the mechanism by which adhesion strength was minimized by these adhesion modifiers and/or by minimal first layer weld penetration.

Vickers hardness values were measured at 1 millimeter increments across the 3-D printed cube along the lines depicted in Figure 4.

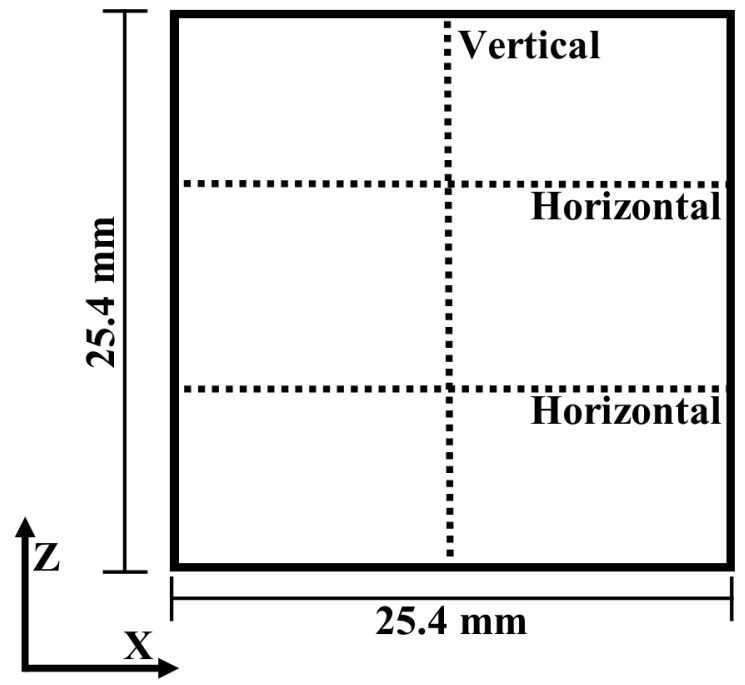

Figure 4. Schematic diagram describing lines along which hardness measurements were taken. 
Preprint: A.S. Haselhuhn, B. Wijnen, G. C. Anzalone, P. G. Sanders, J. M. Pearce, In Situ Formation of Substrate Release Mechanisms for Gas Metal Arc Weld Metal 3-D Printing. Journal of Materials Processing Technology. 226, pp. 50-59 (2015) DOI: 10.1016/j.jmatprotec.2015.06.038

A diamond indenter with 50 gmf and a 10 second dwell time was used to measure macro-hardness to evaluate hardness changes throughout the cube result resulting from process parameters. These test parameters were unlikely to detect the effects of thin interlayer or interfacial compounds present in the specimen. Any bulk compounds that may have formed in the first layer in situ, such as oxides and intermetallics, may affect the hardness of the material. Re-melting of layers that occurred as a result of the welding process can cause these compounds to mix and be dispersed among subsequent layers.

An additional representative specimen from each treatment group was used to measure ultrasonic modulus. This type of test was non-destructive and did not produce fracture surfaces. The top and bottom surfaces of the cube specimens were cut to be parallel with one another and polished to 600 grit with silicon carbide in order to provide a good interface for the transducers. An Olympus Panametrics Pulser Receiver 5052PR was used to measure both the transverse and longitudinal elastic wave velocities in the vertical direction of the specimen. A $2.25 \mathrm{GHz}$ transducer with a molasses couplant was used to induce and measure transverse waves within the specimen whereas a $5 \mathrm{GHz}$ transducer with Panametrics Ultrasonic Couplant D Gel was used to induce and measure longitudinal waves within the specimen. Poisson's ratio $(v)$ was calculated from the transverse velocity $\left(V_{T}\right)$ and longitudinal velocity $\left(V_{L}\right)$ according to Equation 5 (Krautkrämer and Krautkrämer, 1990).

$$
v=\frac{1-2\left(\frac{V_{T}}{V_{L}}\right)^{2}}{2-2\left(\frac{V_{T}}{V_{L}}\right)^{2}}
$$

Using this calculated value, the longitudinal velocity, and the measured specimen density ( $\rho$ ) from the previous Archimedes density measurement (Equation 3), Young's modulus of the material (E) was calculated (Equation 6$).$

$$
E=V_{L}^{2} \rho \frac{(1+v)(1-2 v)}{1-v}
$$

The shear modulus $(G)$ was a function of the transverse velocity and the specimen density (Equation 7).

$$
G=V_{T}^{2} \rho
$$

\section{Results}

\section{Dimensional Validation \& 3-D Printed Part Inspection}

The print parameters employed produced specimens with good dimensional tolerances. The aluminum cubes averaged $28.3 \times 28.3 \times 27.7 \mathrm{~mm}$ in size $( \pm 0.9 \mathrm{~mm})$ whereas the steel cubes averaged $26.3 \times 26.1 \times 26.3 \mathrm{~mm}$ in size $( \pm 0.5 \mathrm{~mm})$. Less dimensional variation was observed in the steel specimens than the aluminum specimens. No warping of the substrate or the printed part was observed during printing or after specimen removal. In many instances, such as parts produced without shield gas for the first layer, the print substrate surface was almost completely unaffected by the welding process. Upon subsequent cleaning with a degreasing agent, the underlying metal was clean, glossy, and could be reused. The surface topology of the bottom surface of the cube (the face in contact with print substrate) varied significantly based upon the mechanism studied (Figure 5). Aluminum specimen A and steel specimen B in Figure 5 were printed without shield gas for the first layer with specimen B printed at different welder settings. This treatment resulted in the smoothest interface compared with aluminum specimens $C$ and D, which employed the use of intermetallic formation and ceramic coatings, respectively. Representative images for steel and aluminum specimens produced in the control group were not imaged as these specimens could only be removed from the substrate by cutting them off. 
Preprint: A.S. Haselhuhn, B. Wijnen, G. C. Anzalone, P. G. Sanders, J. M. Pearce, In Situ Formation of Substrate Release Mechanisms for Gas Metal Arc Weld Metal 3-D Printing. Journal of Materials Processing Technology. 226, pp. 50-59 (2015) DOI: 10.1016/j.jmatprotec.2015.06.038

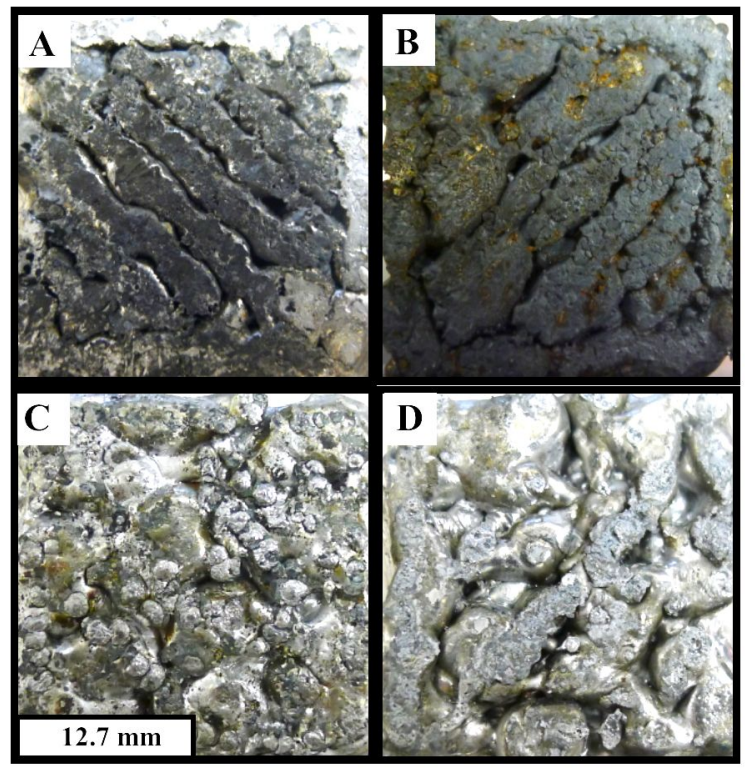

Figure 5. Macro images of the interface between the 3-D printed part and the substrate. A: Aluminum, no shield gas used for the $1^{\text {st }}$ layer, B: Steel, no shield gas used for the $1^{\text {st }}$ layer, C: Aluminum-iron intermetallics, D: Coated aluminum.

\section{Specimen-Substrate Impact Energy}

All specimens, barring the steel and aluminum control group specimens, were readily removed by the Charpy apparatus (Figure 6). Representative specimens from each specimen could also be removed from the substrate either by hand or with minimal assistance from a handheld $1 \mathrm{lb}$ hammer. As previously mentioned, both the aluminum and steel specimens printed in the control group without any adhesion modifiers could not be removed from the substrate by the test apparatus. In fact, these specimens could not be removed from the substrate even when the hammer type was changed to a $5 \mathrm{lb}$ sledgehammer (approximately $40 \mathrm{~J}$ of applied impact energy). These specimens could only be removed from the substrate by cutting, in this case with a horizontal band saw. Although the aluminum and steel specimens printed without first-layer shield gas could be readily removed, they required more energy than other substrate release mechanisms (with aluminum being the highest). Aluminum printed on steel, (intermetallic formation), required the least amount of energy to remove. Although coatings all enabled lowenergy release, there was no statistical difference in removal energy between the coating types on aluminum substrates. 
Preprint: A.S. Haselhuhn, B. Wijnen, G. C. Anzalone, P. G. Sanders, J. M. Pearce, In Situ Formation of Substrate Release Mechanisms for Gas Metal Arc Weld Metal 3-D Printing. Journal of Materials Processing Technology. 226, pp. 50-59 (2015) DOI: 10.1016/j.jmatprotec.2015.06.038

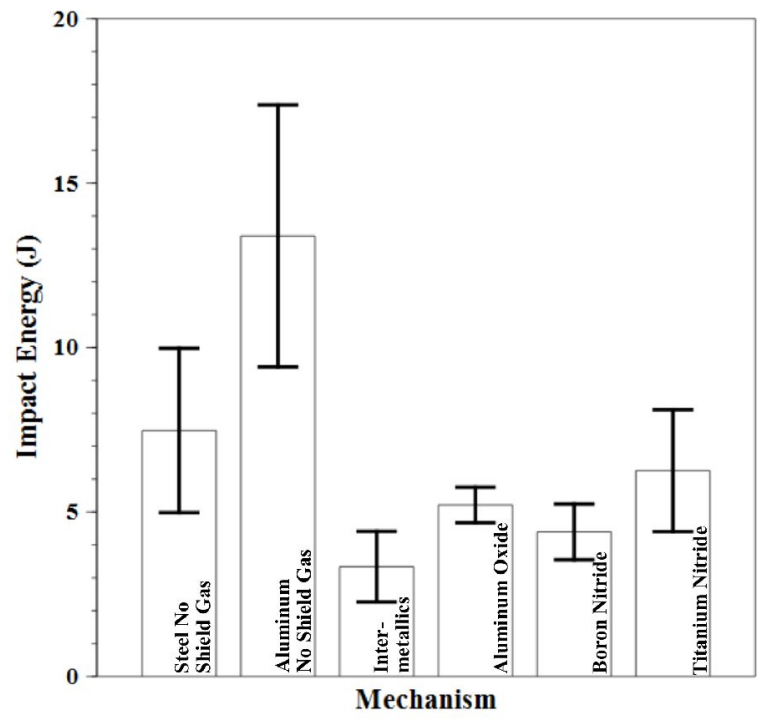

Figure 6. Impact energy required to remove 3-D printed specimens from a print substrate based upon substrate release mechanism employed. Error bars represent \pm 2 standard error (95\% confidence interval).

\section{Specimen Porosity}

All samples had less than $5 \%$ porosity ( $>95 \%$ dense) (Figure 7). Overall, the porosity of the steel specimens was less than that of the aluminum specimens. The control group porosity was less than those produced with no shield gas for the first layer. This trend was statistically significant with the steel specimens but not the aluminum specimens. The porosity of aluminum on a steel substrate (intermetallic formation) was significantly less than aluminum specimens with other substrate release mechanisms. This porosity may appear lower due to the presence of dense iron-containing compounds into the aluminum part. There was no statistical difference in aluminum specimen porosity based upon ceramic coating type.

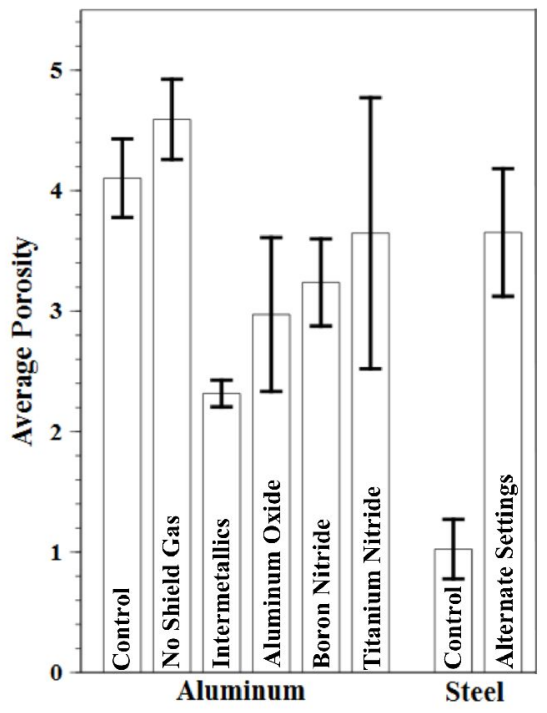

Figure 7. Average specimen porosity measured via the Archimedes method for aluminum (left) and steel (right). Error bars represent \pm 2 standard error (95\% confidence interval). 
Preprint: A.S. Haselhuhn, B. Wijnen, G. C. Anzalone, P. G. Sanders, J. M. Pearce, In Situ Formation of Substrate Release Mechanisms for Gas Metal Arc Weld Metal 3-D Printing. Journal of Materials Processing Technology. 226, pp. 50-59 (2015) DOI: 10.1016/j.jmatprotec.2015.06.038

\section{Specimen Microstructure}

Optical microscopy revealed a banded microstructure in both the aluminum and steel specimens (Figure 8), although this texture was more prevalent in the aluminum specimens. These regions were composed of bands having smaller microstructural features, such as dendrites in aluminum and grain boundaries in steel, sandwiched between bands with larger microstructural features. These banded regions also varied from one another in terms of feature orientation, such as dendritic cell orientation within the aluminum specimens. Banded regions formed due to the unique thermal cycles associated with GMAW wherein portions of the previous layer are re-melted when a new layer is welded onto the part. The layers did not perfectly coincide with each print layer and there was a slight curvature to the banded regions at the specimen edges, presumably due to a faster cooling rate. The steel specimens were dominated by polygonal ferrite near the center, with the polygonal ferrite transitioning to acicular ferrite near the edges and interfaces where faster cooling rates dominated. The polygonal ferrite was banded, similar to the aluminum specimens, although less pronounced.

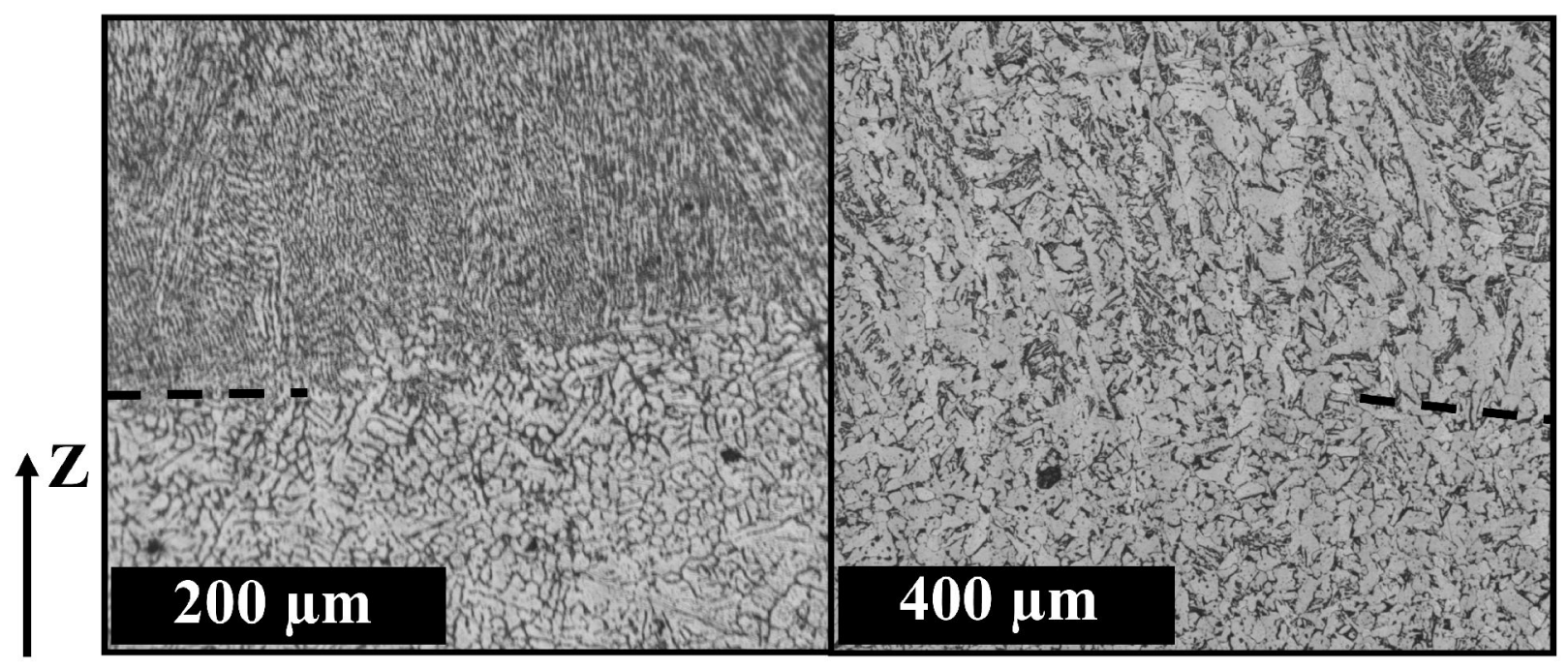

Figure 8. Representative microstructure of an aluminum specimen (left) and a steel specimen (right). Lines added to the figures indicate where boundaries exist. Faster cooling occurred in the $+\mathrm{Z}$ direction.

The microstructural images of aluminum and steel specimens control group showed the alloy without any inclusions or defects. Specimens produced without first layer shield gas exhibited a disproportionate amount of porosity in the first layer as compared to the rest of the specimen. As subsequent layers were printed with the benefit of shield gas, this phenomena did not reoccur. Some oxides were visible by direct observation on the bottom surface of both the aluminum and steel specimens, but these could not be confirmed with EDS.

For aluminum printed on steel (intermetallic formation) an iron gradient was observed within the first 10 microns of the interface with the substrate (Figure 9). The densest layer closest to the part-substrate interface was the most iron rich with approximately 32\% iron. This iron rich layer yielded to a second layer with lower iron concentration further into the sample specimen. EDS analysis could not detect iron beyond these two layers. Structural analyses were not performed on these layers to determine their chemical structure. The aluminum specimens printed on ceramic coated aluminum substrates had similar macrostructures to those prepared by without first layer shield gas. However, many of these specimens exhibited small ceramic coating particles mixed within the first few millimeters of the specimen. 


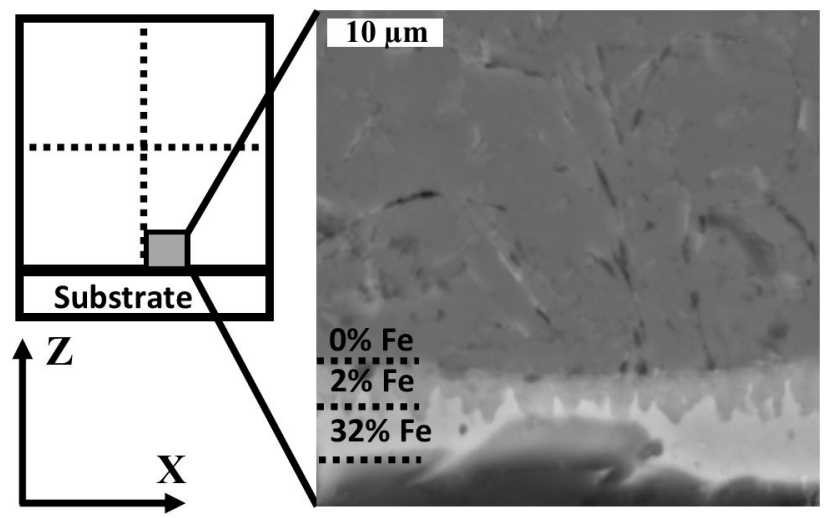

Figure 9. Scanning electron images of aluminum specimens printed on steel near the specimen center. White and lighter colored layers correspond to phases rich in iron.

\section{Specimen Hardness}

For both printed aluminum and steel, more variation in hardness was observed in the vertical direction than in the horizontal direction (Figure 10). No significant long range trends were observed in the hardness measurements of the aluminum specimens. There are many short range increases and decreases in the hardness values that are related to the print layer interval. In aluminum, harder regions corresponded to microstructural regions with smaller dendrite sizes whereas softer regions corresponded to microstructural regions with larger dendrite sizes. A similar trend was exhibited in steel with harder regions corresponding to smaller grain structures. Additionally, the hardness of the steel specimens increased near the specimen edges where acicular ferrite was dominant.
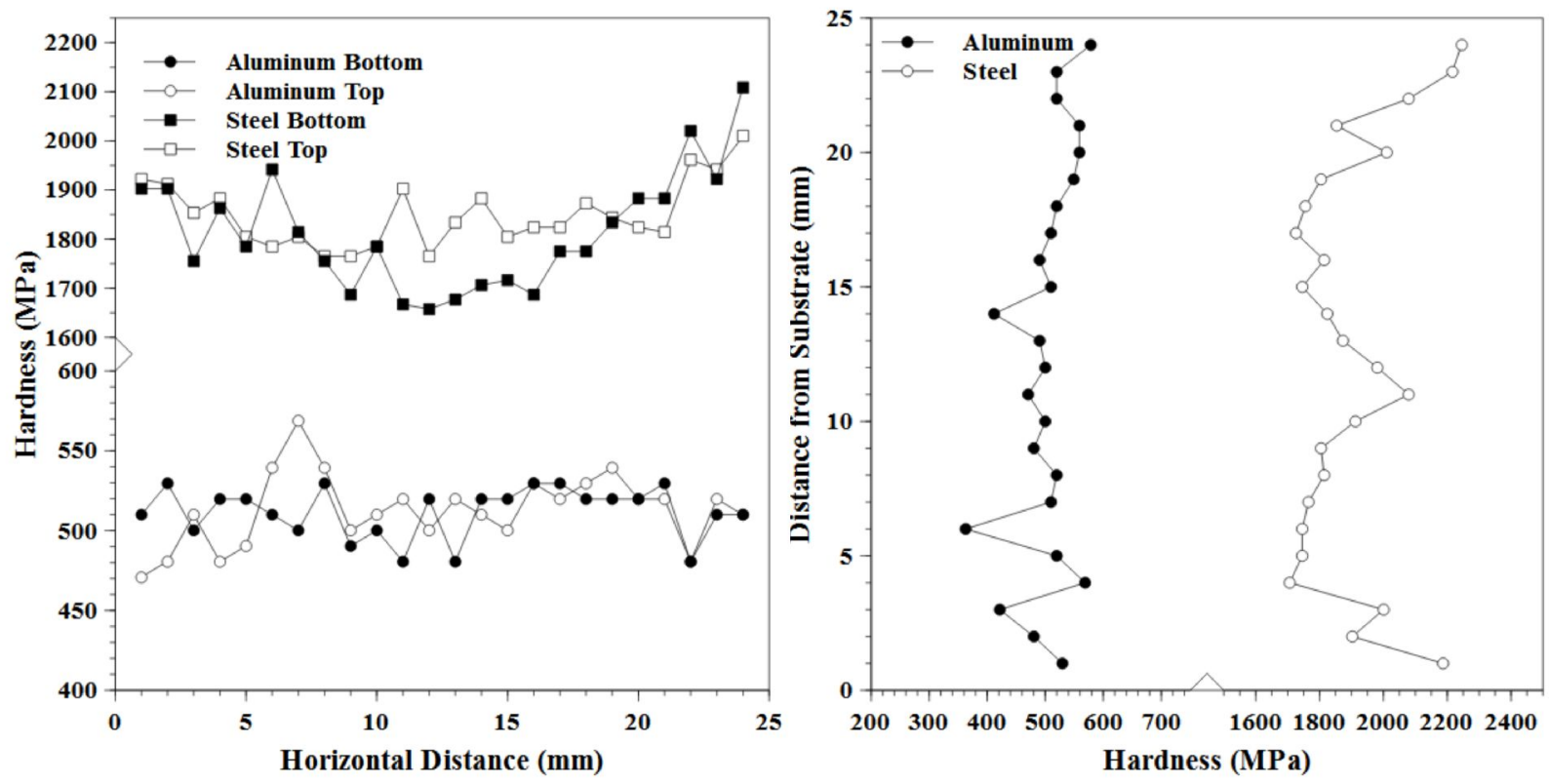

Figure 10. Representative hardness profiles in the horizontal direction (left) and vertical direction (right). The aluminum specimen was printed on boron nitride coated aluminum whereas the steel specimen was printed with alternate settings for the first layer.

\section{Ultrasonic Modulus}

There was a significant difference in both the elastic and shear moduli based upon the substrate release mechanism utilized and this phenomenon was more pronounced in aluminum than steel (Figure 11). The aluminum 
Preprint: A.S. Haselhuhn, B. Wijnen, G. C. Anzalone, P. G. Sanders, J. M. Pearce, In Situ Formation of Substrate Release Mechanisms for Gas Metal Arc Weld Metal 3-D Printing. Journal of Materials Processing Technology. 226, pp. 50-59 (2015) DOI: 10.1016/j.jmatprotec.2015.06.038

and steel moduli were significantly lower for the specimens produced without shield gas and alternate settings for the first layer compared with the control group specimens. Both the elastic and shear moduli of the aluminum specimen printed on steel were larger than both the aluminum specimen printed without shield gas and the aluminum specimen printed on coated substrates. However, the aluminum specimen printed on steel exhibited a smaller elastic and shear modulus compared to the aluminum control group. There was no statistical difference between the moduli of aluminum specimens printed on boron nitride and titanium nitride and these moduli were larger than the moduli of aluminum specimens printed on aluminum oxide. The elastic modulus of the aluminum specimens was approximately $71 \mathrm{GPa}$ whereas the elastic modulus of the steel specimens was approximately 208 $\mathrm{GPa}$. The shear modulus of the aluminum specimens was on the order of $27 \mathrm{GPa}$ whereas for steel this value was approximately $80 \mathrm{GPa}$.
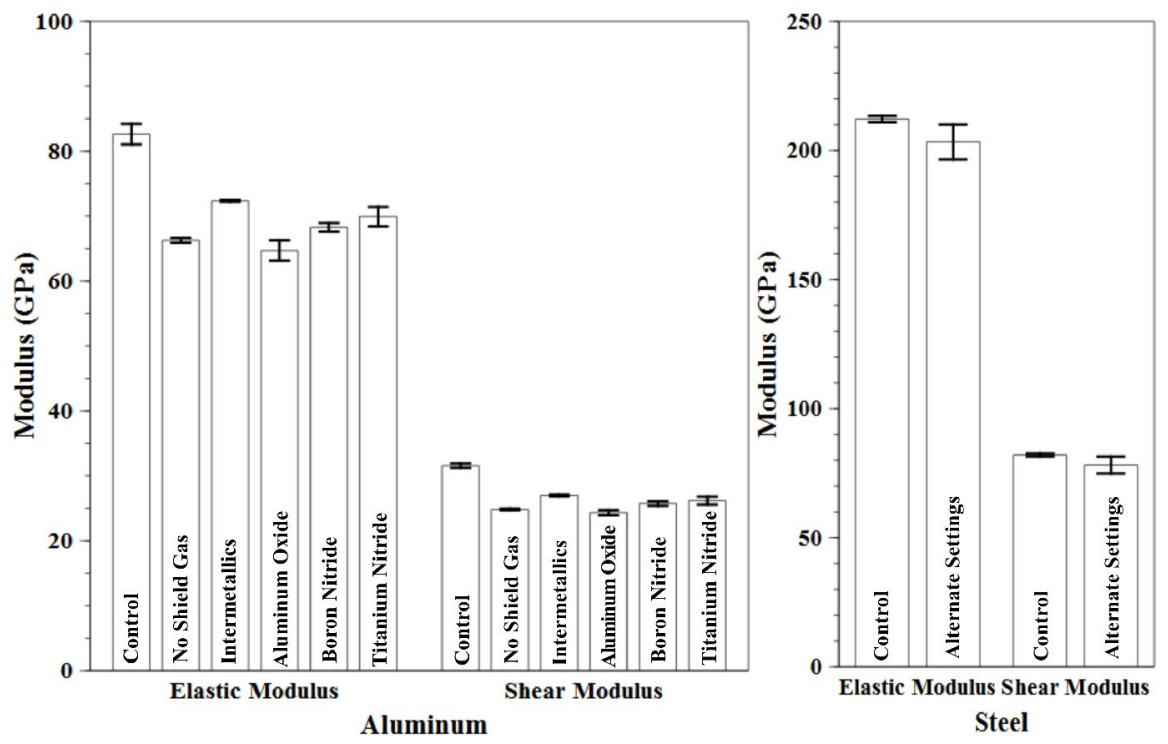

Figure 11. Elastic and shear moduli for aluminum (left) and steel (right) specimens. Error bars represent \pm 2 standard error (95\% confidence interval).

\section{Discussion}

Steel print resolution was superior to that of aluminum. The lower viscosity of molten aluminum allows it to spread, influencing the final dimensions of the part. Liquid metal viscosity can be controlled by alloying additions to improve print resolution.

For the control settings, no atmospheric reactions were encouraged to produce oxides or materials added to limited weld penetration into the substrate. Therefore, a strong bond formed between the 3-D printed part and the substrate. These parts were compositionally homogeneous compared with parts printed via other substrate release mechanisms with no intermetallics, oxides, or ceramic particles dispersed throughout the specimen. These parts exhibited microstructures as shown in Figure 8 and hardness as shown in Figure 10. Both the steel and aluminum control specimens were harder than parts produced with the proposed substrate release mechanisms. As these specimens had to be cut from the substrate, any interface defects were removed.

A combination of effects allowed specimens produced without first layer shield gas and alternate settings to be easily removed from the substrate. With steel, less weld power was used and more weld material was deposited while printing the first layer. For both aluminum and steel, while some oxides may have formed as a result of no shield gas use, arc stability was reduced which prevented weld bead penetration into the substrate. The melted weld wire had little interaction with the substrate thus forming a weak bond. Iron oxide and aluminum oxide compounds were visually observed on the bottom surface of the steel and aluminum specimens respectively. Without the use of 
Preprint: A.S. Haselhuhn, B. Wijnen, G. C. Anzalone, P. G. Sanders, J. M. Pearce, In Situ Formation of Substrate Release Mechanisms for Gas Metal Arc Weld Metal 3-D Printing. Journal of Materials Processing Technology. 226, pp. 50-59 (2015) DOI: 10.1016/j.jmatprotec.2015.06.038

shield gas there was nothing to inhibit the hot weld material from reacting with ambient air. The hot metal reacted with moisture and oxygen in the atmosphere. The moisture decomposed into hydrogen gas that was more soluble in the molten metal than in the solid metal. This solubility gap allowed hydrogen bubbles to nucleate upon directional solidification forming elongated pores that were not present elsewhere in the sample. Compared to steel, this type of porosity was more pronounced in aluminum given its sensitivity to hydrogen porosity. Printing without first layer shield gas produced more porous specimens than those printed with other substrate release mechanisms, regardless of material. The significantly higher porosity in the steel specimen likely caused the strengths of these specimens to be lower than those produced in the control group.

The aluminum specimen printed on steel behaved similarly to aluminum printed without first layer shield gas. However aluminum printed on steel exhibited less weld penetration and the aluminum did not wet the steel substrate as well. This produced a rougher surface texture at the interface between the first layer and the print substrate as compared to parts produced without first layer shield gas. Taban et al. (2010) and Pasic et al (2007) described the difficulty of joining aluminum and steel by traditional welding methods. It was expected that if a joint formed, aluminum would form a very weak interface dominated by the formation of aluminum iron intermetallics (Taban, et al. 2010). These intermetallics form due to the significant chemical, physical, and geometric differences between aluminum and iron (Pasic, et al. 2007). An iron composition gradient was observed over the first ten microns of the aluminum specimens printed on steel substrates, with as much as 32\% iron in the aluminum directly adjacent to the steel substrate (Figure 8). Aluminum iron intermetallics comprised of approximately 33\% iron have been defined by Pasic et al as being of the $\mathrm{FeAl}_{2}$ type (2007). As iron is denser than aluminum, the iron-rich layers likely decreased the apparent porosity of these specimens, and may have artificially increased the moduli of these specimens.

The direct application of oxides and nitrides to the surface was expected to limit weld penetration by forming a barrier between the substrate and the weld material. There was little statistical difference in part quality or impact energy required to remove the specimen from the substrate based upon the type of ceramic coating used. The use of aluminum oxide with a chemical binder appeared to work well to prevent adhesion between the print material and the substrate as proposed by Haselhuhn et al. (2014). Compositional analysis of the specimens indicated that some of the coating particles may have been dislodged from the substrate by the welding process, with these particles being mixed within the first two millimeters above the substrate.

The elastic and shear moduli of all specimens agree well with those reported in the literature (Table 3).

Table 3. Aluminum and Steel Modulus Values as Reported in the Literature

Material

$\mathrm{Al}-5 \% \mathrm{Si}$

ER4043 Al

Mild Steel

Low Carbon Steel

ER70S-6 Steel

\section{Elastic Modulus (GPa)}

71

71

208-209

207.1

208
Shear Modulus (GPa)

26.2

81-82

$-$

80

\section{Reference}

Gale \& Totemeier (2003)

This study

Gale \& Totemeier (2003)

Wolfenden \& Schwanz (1995)

This study

Modulus measurements via ultrasonic methods are sensitive to interfaces and defects within the specimen such as micro porosity. Both macro-porosity, the result of poor in-fill between weld beads, and micro-porosity due to soluble gases, were observed in the specimens. Defects such as micro porosity and poor infill can reduce a material's moduli by lowering resistance to elastic deformation. Future testing of specimens printed via GMAW-based 3-D metal printing should include tensile and compression testing to obtain a more thorough understanding of the mechanical properties of printed parts.

Variations in specimen hardness relate directly to local microstructure. As previously described, regions with a finer microstructure had correspondingly higher hardness in both aluminum and steel. While there were no long-range macroscopic trends in aluminum, steel specimens were hardest near edges where acicular ferrite was dominant due to the faster cooling rate. This banded microstructure has been reported by other researchers for 3-D 
Preprint: A.S. Haselhuhn, B. Wijnen, G. C. Anzalone, P. G. Sanders, J. M. Pearce, In Situ Formation of Substrate Release Mechanisms for Gas Metal Arc Weld Metal 3-D Printing. Journal of Materials Processing Technology. 226, pp. 50-59 (2015) DOI: 10.1016/j.jmatprotec.2015.06.038

printed metal specimens. Choi et al. (2001) reported a similar banded microstructure in their mild steel parts produced via laser welding and milling. Similarly, a finer grain structure was observed in the center of the weld bead with coarser grain structures dominant at the intersections between weld beads. These banded microstructures correspond to thermal gradients produced as subsequent layers are printed. Any curvature associated with these banded regions is dependent upon the path the printer follows while printing. Knowledge of this effect can be used by designers to develop print paths that optimize microstructure and properties. It may be possible to tailor print methods to deliver part or all of some heat treatment processes.

Printing without first layer shield gas and facilitating aluminum-iron compound formation by printing aluminum on steel substrates were shown to be effective methods for enabling easy removal of printed parts from substrates. These methods were the least expensive of those examined; the coatings investigated can be quite costly. Regardless, all of the methods investigated were much less expensive than cutting parts from their substrates and subsequent post-printing treatment.

All of these methods, however, reduce the total cost of metal 3-D printing into the range accessible to small and medium sized enterprises and businesses. For the first time it makes metal printing in addition to plastic printing (Pearce, et al. 2010) of open source appropriate technologies (Pearce, 2012) and education (Canessa, et al., 2013) viable for sustainable development (King et al., 2014) and for low-cost laboratory supplies (Pearce, 2014). Most notably, the minimal weld penetration allowed all of the print substrates to be reused to print additional parts, although the substrates were not reused in this study. This has significant cost savings potential and it is clear that it qualitatively reduces the environmental impact of 3-D metal printing. Previous work has shown improved constrained sustainability (Reeves, 2009), reduced carbon emissions (Reeves, 2012), reduced environmental impact using 3-D printing for prototyping (Drizo \& Pegna, 2006), distributed manufacturing (Kreiger and Pearce, 2013) and global sustainability (Gebler, Uiterkamp, \& Visser, 2014) as compared conventional methods of manufacturing in plastic and metal. Future work should consider a full life cycle analysis of GMAW 3-D printing.

Future work should also quantitatively evaluate the residual stresses during GMAW-based metal 3-D printing. In the present study there was no observed accumulation of residual stress in the parts during printing or upon removal from the print substrate, and part distortion did not occur. Residual stresses should be minimized within 3-D printed specimens as these stresses may prematurely remove the part from the substrate. This residual stress can also pose a significant issue for 3-D printed parts produced via laser sintering methods as described by Mercelis and Kruth (2006) and Wu et al. (2014), where they observed that upon cutting the part from the print substrate, the residual stresses caused the part to distort. Mercelis and Kruth (2006) explain that reducing thermal gradients may be critical to also reducing residual stress buildup whereas Wu et al. note that many more factors such as part size and the print time affect the formation of residual stresses (2014). Both in situ heating (Vasinonta et al., 2006) and ex situ annealing steps (Shiomi et al., 2004) have been utilized to reduce residual stresses of 3-D laser sintered parts. The extended thermal cycle associated with GMAW-based 3-D printing may serve as a stress relief treatment that is effective for small parts, such as the cubes printed in this study. Residual stress measurement during printing and cooling can properly evaluate the impact these stresses have upon print quality.

Future work is necessary to determine if these substrate release mechanisms can be applied to other 3-D printing platforms to minimize the amount of energy required to remove a part from the print substrate. Methods that involve ambient atmosphere, would not be suitable for electron beam welding or laser sintering as they may result in dangerous environments or equipment damage. Methods that involve coatings, may be suitable although care should be given to minimize thermal decomposition of coatings and to ensure the thermal decomposition products do not form a combustible atmosphere. The impact of coating roughness and uniformity on metal 3-D printed part geometry may be a greater issue with high-resolution 3-D printing platforms such as electron beam welding and laser sintering. The impact of coating roughness and uniformity could not be quantified with this GMAW-based metal 3-D printer due to the current resolution limitations of this technology but this should be evaluated in the future. Methods that involve laser sintering or electron beam melting of dissimilar metals, may be most suitable to adoption by other 3-D metal printing platforms. Encouraging the formation of intermetallic compounds, such as by printing ferrous-based or aluminum-based materials on titanium, may allow the specimen to be removed from the substrate with ease. 
Preprint: A.S. Haselhuhn, B. Wijnen, G. C. Anzalone, P. G. Sanders, J. M. Pearce, In Situ Formation of Substrate Release Mechanisms for Gas Metal Arc Weld Metal 3-D Printing. Journal of Materials Processing Technology. 226, pp. 50-59 (2015) DOI: 10.1016/j.jmatprotec.2015.06.038

\section{Conclusions}

This study expanded upon previous work on low-cost substrate release mechanisms for GMAW-based 3-D metal printing. No-cost methods were also developed that eliminate the need for coatings: manipulation of first layer weld settings and aluminum-iron compound formation. Print settings, such as printing without shield gas and using alternate weld unit settings for the first layer, were developed to limit weld penetration into the substrate and to encourage in situ formation of release agents such as oxides. Encouraging the formation of aluminum-iron compounds allowed aluminum specimens to be removed from steel substrates with the lowest impact energy. These mechanisms allowed the steel and aluminum specimens to be removed from the substrate without the use of cutting tools. Low-cost methods, such as the use of aluminum oxide, boron nitride, and titanium nitride coatings, were also found to be effective substrate release agents for aluminum 3-D printing as long as a chemical binder was present in the coating solution. These substrate release mechanisms further democratize 3-D printer manufacturing, as they are suited for consumers as well as small and medium enterprises. In addition to reducing the overall costs of producing 3-D metal parts, these substrate release mechanisms also minimized the waste and concomitant environmental impact associated with 3-D metal printing by yielding substrates suitable for reuse.

\section{Acknowledgments}

The authors would like to acknowledge T. Wood, P. Fraley, T. Pinar, K. Deane, and P. Quimby for technical assistance and valuable discussions with R. Gorham at America Makes. The authors would also like to acknowledge support and technical assistance from the Miller Electric Manufacturing Company. This material is based on research sponsored by Air Force Research Laboratory under agreement number FA8650-12-2-7230. The U.S. Government is authorized to reproduce and distribute reprints for Governmental purposes notwithstanding any copyright notation thereon. The views and conclusions contained herein are those of the authors and should not be interpreted as necessarily representing the official policies or endorsements, either expressed or implied, of Air Force Research Laboratory or the U.S. Government.

\section{Author Disclosure Statement}

No conflicts of interest exist.

\section{References}

Anzalone G.C., Zhang C., Wijnen B., Sanders, P.G., Pearce, J.M. (2013). A low-cost open-source metal 3-D printer. IEEE Access 1, 803-810.

ASTM B962-13. Standard Test Methods for Density of Compacted or Sintered Powder Metallurgy (PM) Products Using Archimedes’ Principle, ASTM International, West Conshohocken, PA, 2013, www.astm.org.

Berman, B. (2012). 3-D printing: The new industrial revolution. Business Horizons, 55, 155-162.

Campbell, T., Williams, C., Ivanova, O., \& Garrett, B. (2011). Could 3D printing change the world?. Technologies, Potential, and Implications of Additive Manufacturing. Washington, DC: Atlantic Council.

Canessa, E., Fonda, C., \& Zennaro, M. (2013). Low--cost 3D printing for science, education and sustainable development. Low-Cost 3D Printing, 11.

Choi, D. S., Lee, S. H., Shin, B. S., Whang, K. H., Song, Y. A., Park, S. H., \& Jee, H. S. (2001). Development of a direct metal freeform fabrication technique using $\mathrm{CO} 2$ laser welding and milling technology. Journal of Materials Processing Technology, 113(1), 273-279.

Drizo, A., \& Pegna, J. (2006). Environmental impacts of rapid prototyping: an overview of research to date. Rapid Prototyping Journal, 12(2), 64-71.

Gale W.F., and Totemeier, T.C. (Eds.). Smithells metals reference book, $8^{\text {th }}$ Ed., Butterworth-Heinemann, 2003, 14:16-15:3. 
Preprint: A.S. Haselhuhn, B. Wijnen, G. C. Anzalone, P. G. Sanders, J. M. Pearce, In Situ Formation of Substrate Release Mechanisms for Gas Metal Arc Weld Metal 3-D Printing. Journal of Materials Processing Technology. 226, pp. 50-59 (2015) DOI: 10.1016/j.jmatprotec.2015.06.038

Gebler, M., Uiterkamp, A. J. S., \& Visser, C. (2014). A global sustainability perspective on 3D printing technologies. Energy Policy 74, 158-167.

Haselhuhn, A.S., Gooding, E.J., Glover, A.G., Anzalone, G.C., Wijnen, B., Sanders, P.G., \& Pearce, J.M. (2014). Substrate release mechanisms for gas metal arc weld 3-D aluminum metal printing. 3-D Printing and Additive Manufacturing, 1(4), 204-209. DOI:10.1089/3dp.2014.0015

Holliday, D.B. (1993). Gas-Metal Arc Welding. In: Olson, D.L., et al. (Eds.), ASM Handbook: Welding, Brazing, and Soldering, vol. 6. ASM International, 180-185.

Jones, R., Haufe, P., Sells, E., Iravani, P., Olliver, V., Palmer, C., \& Bowyer, A. (2011). RepRap-the replicating rapid prototyper. Robotica, 29(01), 177-191.

King, D. L., Babasola, A., Rozario, J., \& Pearce, J. M. (2014). Mobile open-source solar-powered 3-D printers for distributed manufacturing in off-grid communities. Challenges in Sustainability, 2(1), 18-27.

Krautkrämer J, \& Krautkrämer H. (1990). Ultrasonic Testing of Materials ( $4^{\text {th }}$ ed.). New York: Springer-Verlag.

Kreiger, M., \& Pearce, J. M. (2013). Environmental life cycle analysis of distributed three-dimensional printing and conventional manufacturing of polymer products. ACS Sustainable Chemistry \& Engineering, 1(12), 15111519.

Mercelis, P., \& Kruth, J-P. (2006) Residual stresses in selective laser sintering and selective laser melting. Rapid Prototyping Journal, 12(5), 254-265.

O’Brien R.L., (1991). Welding Handbook, $8^{\text {th }}$ Ed., Vol 2. Welding Processes. American Welding Society, Miami, FL, 110-155.

Pasic, O., Hajro, I., \& Hodzic, D. (2007). Welding of dissimilar metals-status requirement, and trend of development. Welding in the World, 51(1), 377-384.

Pearce, J. M., Blair, C. M., Laciak, K. J., Andrews, R., Nosrat, A., \& Zelenika-Zovko, I. (2010). 3-D printing of open source appropriate technologies for self-directed sustainable development. Journal of Sustainable Development, 3(4), 17-29.

Pearce, J. M. (2012). The case for open source appropriate technology. Environment, Development and Sustainability, 14(3), 425-431.

Pearce, J. M. (2014). Open-source lab: How to build your own hardware and reduce research costs. Elsevier.

Peels, J. (23 May 2014). Metal 3D printing: From lab to fab. Inside 3DP. Retrieved from http://www.inside3dp.com/metal-3d-printing-lab-fab/.

Rasband, W.S., Image J., U.S. National Institutes of Health, Bethsesda, Maryland, USA, http://imagej.nih.gov/ig/, 1997-2014.

Ratto, M., \& Ree, R. (2012). Materializing information: 3D printing and social change. First Monday, 17(7).

Reeves, P. (2009). Additive manufacturing-A supply chain wide response to economic uncertainty and environmental sustainability. Econolyst Limited, The Silversmiths, Crown Yard, Wirksworth, Derbyshire, DE4 4ET, UK.

Reeves, P. (2012). Example of econolyst research-Understanding the benefits of AM on CO2 Econolyst Ltd., Derbyshire, UK (2012) http://www.econolyst.co.uk/resources/documents/files/Presentation\%20-\%20Nov \%202012\%20-\%20TCT\%20conference\%20UK\%20-\%20AM\%20and\%20carbon\%20footprint.pdf

Reprap Org. Rostock, http://reprap.org/wiki/Rostock, last accessed October 23, 2014. 
Preprint: A.S. Haselhuhn, B. Wijnen, G. C. Anzalone, P. G. Sanders, J. M. Pearce, In Situ Formation of Substrate Release Mechanisms for Gas Metal Arc Weld Metal 3-D Printing. Journal of Materials Processing Technology. 226, pp. 50-59 (2015) DOI: 10.1016/j.jmatprotec.2015.06.038

Sachs, E., Cima, M., Williams, P., Brancazio, D., \& Cornie, J. (1992). Three dimensional printing: rapid tooling and prototypes directly from a CAD model. Journal of Manufacturing Science and Engineering, 114(4), 481488.

Shiomi, M., Osakda, K., Nakamura, K., Yamashita, T., \& Abe, F. (2004). Residual stress within metallic model made by selective laser melting process. CIRP Annals - Manufacturing Technology, 51(1), 195-198.

Taban, E., Gould, J.E., \& Lippold, J.C. (2010). Dissimilar friction welding of 6061-T6 aluminum and AISI 1018 steel: Properties and microstructural characterization. Materials \& Design, 31, 2305-2311.

Vasinonta, A., Beuth, J.L., \& Griffith, M. (2006). Process maps for predicting residual stress and melt pool size in the laser-based fabrication of thin-walled structures. Journal of Manufacturing Science and Engineering, 129(1), 101-109.

Wittbrodt, B. T., Glover, A. G., Laureto, J., Anzalone, G. C., Oppliger, D., Irwin, J. L., \& Pearce, J. M. (2013). Lifecycle economic analysis of distributed manufacturing with open-source 3-D printers. Mechatronics, 23(6), 713-726.

Wohlers, T., \& Caffrey, T. (2014). Wohlers Report 2014 Annual Worldwide Progress Report. Wohlers Associates, Inc. Fort Collins, CO.

Wolfenden, A., \& Schwanz W.R.. (1995). An evaluation of three methods to measure the dynamic elastic modulus of steel. Journal of Testing and Evaluation, 23, 176-179.

Wu, A.S., Brown, D.W., Kumar, M., Gallegos, G.F., \& King, W.E. (2014). An experimental investigation into additive manufacturing-induced residual stresses in 316L stainless steel. Metallurgical and Materials Transactions A, 45(13), 6260-6270. 